\title{
Qué es lo que en realidad están haciendo sentados ahí? Um gesto provocativo na obra de Mario Bellatin.
}

Qué es lo que en realidad están haciendo sentados ahí? A provocative gesture in the work of Mario Bellatin.

Pedro Xavier da Cunha

(UFSC) 


\section{Resumo}

O presente trabalho se propõe a iniciar uma investigação sobre a presença de um gesto provocativo na obra do escritor mexicano Mario Bellatin. Essa hipótese parte da leitura dos textos Underwoord Portátil, modelo 1915 (2005), Disecado (2011) e Escribir sin escribir (2014). A presença do gesto é buscada inicialmente nos relatos de alguns Eventos de Escritura presentes nos textos selecionadosm que o. O gesto está pensado a partir de duas dimensões inter-relacionadas: a) a provocação através da construção de uma figura autoral ambígua; e b) a provocação através de determinados procedimentos de escritura. A discussão nos leva a sugerir que o gesto provocativo bellatiniano atua uma busca pela condição comunitária da escritura.

Palavras-chave: Mario Bellatin; Eventos de Escritura; mito do escritor; comunidade

\section{Resumen}

El presente trabajo propone empezar una investigación acerca de la presencia de un gesto provocativo en la obra del escritor mexicano Mario Bellatin. Esta hipótesis parte de la lectura de los textos Underwood Portátil, modelo 1915 (2005), Disecado (2011) e Escribir sin escribir (2014). La presencia del gesto es buscada inicialmente en los relatos de algunos Sucesos de Escritura presentes en los textos seleccionados. El gesto está pensado a partir de dos dimensiones interrelacionadas: a) la provocación a través de la construcción de una figura autoral ambígua; b) la provocación a través de ciertos procedimientos de escritura. La discusión nos lleva a sugerir que el gesto provocativo bellatiniano actua una búsqueda por la condición comunitária de la escritura.

Palabras-chave: Mario Bellatin; Sucesos de Escritura; mito del escritor; comunidad 
Em Underwood Portátil: Modelo 1915 (2005), do escritor mexicano Mario Bellatin, o narrador nos conta sobre como montou uma de suas ações no templo de San Jerónimo, durante a apresentação do seu livro Perros héroes (2003). Segundo ele, ao final da apresentação, quando o altar do templo ficou vazio, de repente, sob seu comando, de debaixo da mesa saiu uma cadela da raça pastor belga malinois, que saltou sobre o altar e permaneceu ali, imóvel, encarando os espectadores. O narrador, então, admite que, no meio daquela (in)ação, teve muita vontade de se levantar, voltar-se para o público e perguntar, em voz alta, "qué era lo que en realidad estaban haciendo sentados alli’"'.

Esse mesmo relato volta a aparecer em Disecado (2011) e Escribir sin escribir - lo raro es ser un escritor raro (2014), textos que partilham com Underwood Portátil a condição de se situarem em um lugar indefinido entre o ensaio autocrítico e a autoficção, além de tratarem conjuntamente dos livros e das ações extraliterárias de Mario Bellatin ${ }^{2}$. Em Disecado (2011), o narrador nos conta que Bellatin chama essas suas ações de Eventos de Escritura” ${ }^{3}$ os quais dizem respeito a "todos aquellos actos que consistieron en escribir sin utilizar los métodos clásicos de escritura como, por ejemplo, las palabras"'.

Assim, o presente trabalho busca, a partir dos três textos, iniciar uma investigação sobre a presença de um gesto provocativo na repetição dos relatos sobre os Eventos de

1 BELLATIN, Mario. Obra reunida, 2013, p. 497-498.

2 Em linhas gerais, em Underwood Portátil: modelo 1915, ao longo de 95 fragmentos, algumas linhas narrativas intercalam-se entre si, compondo cada qual uma dimensão da relação de um escritor com sua própria escritura. O texto é narrado em $1^{a}$ pessoa e opera um movimento reflexivo sobre a trajetória do escritor mario bellatin até o momento (o nome próprio é escrito com minúscula). As linhas narrativas abordam: o mito de origem de sua escritura ("Quizá todo comenzó cuando tenía diez años [...]" [p. 485]); o processo de elaboração de alguns de seus livros (como Mujeres de sal, Salón de Belleza, Efecto invernadero e Perros Héroes); o caminho de suas ideias acerca de sua própria escritura e do ofício da escrita; acontecimentos de sua vida que são relacionados à sua escritura (como a conversão ao sufismo); algumas ações extra-literárias que realizou (a apresentação de Perros Héroes, o Congreso de dobles de escritores) etc. Disecado é um texto composto por 202 fragmentos e 61 apontamentos breves que, ao final do texto, perfazem uma espécie de recapitulação desviante do livro; é narrado em $1^{a}$ pessoa, mas se refere ao escritor Mario Bellatin como a um outro que é ele mesmo (a ambiguidade da identidade dos dois personagens está condensada no modo pelo qual o narrador se refere a Bellatin no começo do texto: “¿Mi Yo?”). O texto trata de um encontro incerto que o narrador tem com o escritor Mario Bellatin, quem, morto, aparece subitamente sentado na beira de sua cama uma noite, enredado em um monólogo ininterrupto: uma espécie de testemunho póstumo de sua vida e obra. Já em Escribir sin escribir, texto também fragmentário (são 23 fragmentos), um narrador-escritor, também em $1^{\mathrm{a}}$ pessoa, se propõe a refletir sobre sua obra, cotejando-a em diálogo com sua própria vida. Ao longo desta espécie de auto-análise, o autor se pergunta em que consistiria a busca constante por "escrever sem escrever" que o acompanha. Obra e vida a que o narrador alude coincidem com as de Mario Bellatin, mas em nenhum momento o seu nome próprio é mencionado.

3 Ao longo do texto, utilizo o termo "Eventos de Escritura" para traduzir o original "Sucesos de Escritura".

4 BELLATIN, Mario. Obra reunida 2, 2014, p. 214. 
Escritura de Mario Bellatin. Tal gesto será pensado a partir de duas dimensões interrelacionadas: a) a provocação através da construção de uma figura autoral ambígua; e b) a provocação através de determinados procedimentos de escritura. Antes de investigarmos a hipótese de tal gesto provocativo, contudo, se faz necessário o levantamento de alguns pontos e conceitos chave.

\section{O projeto bellatiniano}

A noção de projeto é fundamental para a compreensão de qualquergesto operado na escritura bellatiniana. Andrea Cote Botero ${ }^{5}$ trabalha a obra de Bellatin a partir de dois motes centrais: "la literatura como proyecto" e "el giro hacia el procedimiento". Por obra de Mario Bellatin, podemos entender a sua produção que inclui tanto os livros publicados quanto uma série de ações suas (que estou chamando aqui de Eventos de Escritura). A compreensão da literatura bellatiniana como parte de um projeto único, contudo, dá um passo além. A noção de projeto implica uma abertura que abriga ao mesmo tempo a escritura presente e a possível e, como aponta Cote Botero ${ }^{6}$, implica em uma dupla acepção: por um lado, 'projeto' representa a reunião de toda a produção de Bellatin sob uma mesma totalidade; por outro, refere-se à própria lógica de criação que rege essa produção, que se funda na ação de projetar, ou seja, visionar, traçar, de modo que cada livro é entendido apenas como um elemento, sempre parcial, da experiência, uma pegada de uma escritura que não cessa de lançar-se adiante. Já a virada procedimental que, segundo Cote Botero, é central neste projeto bellatiniano, consiste em " [...] una actitud de autores del presente al involucrarse reflexiva y creativamente en momentos de la elaboración de un libro que están más allá del momento mismo de la escritura" . É como parte desse movimento "extra-literário", ou seja, desse movimento criativo que excede o momento de escrita propriamente dita, que pode ser entendido o procedimentos de auto-apropriação e repetição de Bellatin.

Rafaela Cassia Procknov ${ }^{8}$, por sua vez, propõe que o projeto bellatiniano se caracterizaria principalmente pela ética que o conduz, e que consiste em "viver como artista, em que esse viver suporia se inventar permanentemente sob formas variadas". Procknov defende que tanto as intervenções extraliterárias quanto a escritura de Bellatin

5 COTE BOTERO, Andrea. Mario Bellatin: El Giro Hacia El Procedimiento y La Literatura Como Proyecto, 2014.

6 Ibidem, p. 91.

7 Ibidem, p. 43.

8 PROCKNOV, Rafaela Cassia. Uma estética da existência: vida e escritura em Mario Bellatin, 2013.

9 Ibidem, p. 42. 
fazem parte dessa mesma autoinvenção. Os procedimentos utilizadas por Bellatin segundo ela: estreitamento de outras linguagens artísticas à palavra, autofiguração na escritura - compõem o que, à luz do pensamento de Foucault, Procknov denomina "estética da existência": uma aposta na arte tomada como forma-de-vida, "vida em arte que não supõe divisões, de um modo que uma das partes explique a outra, mas sim propõe a existência de cada parte em si mesma, afirmando esse composto vidaarte, arte-vida" ${ }^{\prime 10}$. É justamente essa dimensão ética - de aposta na vida como vida-emarte, mas também, como mostrarei mais adiante, de democratização do procedimento e afirmação do caráter público da obra -, é essa dimensão que parece estar sendo provocada por Bellatin em sua formulação de um mito pessoal do escritor.

Daniel Link ${ }^{11}$, ao discutir o escritor como uma forma-de-vida, propõe-na em termos de uma ética da escritura ${ }^{12}$. Ética', justamente porque, como diz Giorgio Agamben, através dela uma vida "aceita, irrevogavelmente e sem reservas, pôr-se em jogo nos seus gestos" ${ }^{\prime 3}$. Ou, como formula Deleuze em $A$ vida como obra de arte, ética como um conjunto de regras facultativas que avaliam o que fazemos, o que dizemos, em função dos modos de existência que isso implica ${ }^{14}$. Assim, pensar o projeto bellatiniano a partir de uma ética de escritura - que é também uma ética do vivente e, no caso de Bellatin, uma que se propõe ao composto vida-arte -, implica em abordar o gesto provocativo envolvido na criação do mito pessoal do escritor como algo não desarticulado de toda uma compreensão própria da escritura, da vida e da ficção.

\section{Ficção, autoficção e mito do escritor}

Aqui, a noção de ficção não se opõe à de verdade, enquanto uma reivindicação do falso. Pelo contrário, como pontua César Aira, na ficção "conviven lo verdadero y lo falso, valen lo mismo al mismo tiempo y se transforman uno en el otro" ${ }^{15}$. Entre o empírico e o imaginário, diz Juan José Saer, a ficção assume um caráter paradoxal, pois "se recorre ao falso, o faz para aumentar sua credibilidade" ${ }^{16}$. Através das formulações de Saer, a ficção, como um tratamento específico do mundo, se configura uma antropologia especulativa. Podemos pensar as incursões de Bellatin nos procedimentos

10 Ibidem, p. 43.

11 LINK, Daniel. El escritor como "forma-de-vida", 2015.

12 Essa ética da escritura e da função-escritor, complementa Link, seria, da mesma forma, uma ética do vivente, o que ressalta o composto vida-arte (LINK, Daniel. El escritor como "forma-de-vida", 2015, p. 5).

13 AGAMBEN, Giorgio. "O autor como gesto", 2007, p. 61.

14 DELEUZE, Gilles. "A vida como obra de arte”, 2013, p. 130.

15 AIRA, César. Nouvelles Impressions du Petit Maroc, 2011, p. 33.

16 SAER, “O conceito de ficção”, Revista Sopro, 2009, p.2. 
de auto-figuração enquanto um movimento de especulação de si e da figura do autor ${ }^{17}$ que, contudo, não está desvinculado de uma provocação dirigida ao outro, ao leitor. É uma especulação que se dá em forma de um jogo que resiste à busca por um valor biográfico' ${ }^{18}$ em seus livros, ao mesmo tempo em que, ao invés de descartá-lo, permanece no linde entre o real e o fictício, tensionando-o.

Esse interstício em que se desenvolve a escritura de Bellatin é justamente o espaço instaurado pelo regime estético das artes, proposto por Jacques Rancière em $A$ partilha do sensivel (2009). Para Rancière, se no regime anterior ${ }^{19}$ - aristotélico, representativo - a autonomização das formas de arte garantiu que a ideia de ficção se desvinculasse da dicotomia verdade/mentira, sendo regida apenas pela sua capacidade de verossimilhança; a nova ficcionalidade do regime estético, por sua vez, rompe com o encadeamento causal aristotélico das ações e torna-se apenas uma ordenação de signos, de modo que os modos de construção ficcional (a razão das ficções) e os modos de conexão e apresentação da história, da realidade (razão dos fatos) passam a pertencer a um mesmo regime de sentidos. O regime estético das artes, portanto, instaura uma indistinção tendencial entre a razão das ficções e a razão dos fatos.

O conceito de autoficção, conforme discutido por Diana Klinger ${ }^{20}$, também nos ajuda a dar conta desse interstício desestabilizante, entre a ficção e a autofiguração, em que a escritura de Bellatin se desenvolve (ou se dissolve) ${ }^{21}$. Segundo Klinger, o conceito de autoficção é uma categoria inserida no campo mais amplo das "escritas de si" e, enquanto conceito específico da narrativa contemporânea, só pode ser formulado a partir das críticas desenvolvidas ao longo do século XX acerca das noções de sujeito (a partir de Nietzsche) e representação (a partir de Derrida, leitor de

17 Essa especulação está presente nos textos de Bellatin selecionados para serem estudados aqui. Nas seguintes passagens está até explicitado: “[...] una preocupación que desde hace mucho me acompaña, sobre el posible lugar donde debe encontrarse el escritor frente a sus textos" (BELLATIN, M. Obra reunida, 2013, p. 499); "Es cierto que desde algún tiempo he venido indagando acerca de la relación entre el autor y su texto" (Idem, "Escribir sin escribir", 2014, p. 11).

18 Através do conceito de valor biográfico, Leonor Arfuch (2002) se permite estabelecer equivalências entre os processos de subjetivação envolvidos nas diversas formas narrativas consideradas na sua formulação de um espaço biográfico.

19 Para Rancière, um regime consiste em "um modo de articulação entre maneiras de fazer, formas de visibilidade dessas maneiras de fazer e modos de pensabilidade de suas relações" (RANCIÈRE. $A$ partilha do sensivel: estética e política, 2009, p. 13). Assim, o filósofo distingue três regimes de partilha do sensível, três regimes de identificação das artes na tradição ocidental: o regime ético das imagens (platônico), o regime poético/representativo da arte (aristotélico) e o regime estético das artes. Para Rancière o regime estético seria “o verdadeiro nome daquilo designado pela denominação confusa de modernidade" (Ibidem, p. 34).

20 KLINGER, Diana. Escrita de si como performance, 2008.

21 Não afirmo aqui que a obra de Mario Bellatin possa ser compreendida no gênero da autofição. A princípio, entendo apenas que tal categoria mobiliza discussões relevantes para a investigação dos procedimentos bellatinianos. 
Heidegger). A autoficção se insere, portanto, num movimento de virada etnográfica e de retorno do autor - "auto-referência da primeira pessoa autobiográfica na narrativa contemporânea" 22 -, enquanto questionamento do "recalque modernista do sujeito", da tentativa de, através do desaparecimento do autor, reconhecer a escritura como um apagamento completo da identidade e relevância daquele que escreve ${ }^{23}$. Mas resgatar o autor significa ter de pensá-lo agora a partir da descentralização do sujeito empreendida pelas críticas estruturalista e desconstrucionista. Desse modo, na perspectiva de Klinger, a autoficção surge para dar conta do paradoxo em que a narrativa contemporânea se situa - "entre um desejo narcisista de falar de si e o reconhecimento da impossibilidade de exprimir uma 'verdade' na escrita" 24 -, servindo, simultaneamente, de resposta tanto ao narcisismo midiático marcado pela exaltação do sujeito (a espetacularização da intimidade, discutida por Leonor $\mathrm{Arfuch}^{25}$ ) quanto à crítica ao sujeito.

Luciene Azevedo ${ }^{26}$ realça uma outra dimensão da autoficção que me parece de extrema importância para pensar a obra de Bellatin: a da burla, do engano. A autoficção burla as exigências de qualquer pretensão mimética de modo a desnortear o leitor, violentando o seu horizonte de expectativas. Para Klinger, essa confusão entre as noções de verdade e ficção na autoficção cria uma situação em que o que passa a interessar "não é a relação do texto com a vida do autor, e sim a do texto como forma de criação de um 'mito do escritor"'27. É nesse sentido que a autora entende a autoficção como uma máquina produtora de mitos do escritor, "que funciona tanto nas passagens em que se relatam vivências do narrador quanto naqueles momentos $\mathrm{da}$ narrativa em que o autor introduz no relato uma referência à própria escrita, ou seja, a pergunta pelo lugar da fala (O que é ser escritor? Como é o processo da escrita? Quem diz eu?)"28.

Quando, em Nouvelles Impressions du Petit Maroc (2011), César Aira propõe o escritor como uma proliferação de teorias falsas cujo trabalho é inventar exemplos também falsos dessas teorias que mitifiquem particularidades ${ }^{29}$, a criação de um mito

22 Ibidem, p. 18.

23 Alude-se aqui à contundência com que a morte do autor foi anunciada por Roland Barthes em ensaio homônimo de 1968, em combate ao modo como a autoridade do autor - ou a função-autor, conforme formulou Michel Foucault em O que é um autor? (1969) - servia no espaço literário como "princípio de economia na proliferação do sentido" (FOUCAULT, Michel. “O que é um autor?”, 2009, p. 288).

24 KLINGER, Diana. Escrita de si como performance, 2008, p. 19.

25 ARFUCH, Leonor. O espaço biográfico: dilemas da subjetividade contemporânea, 2010.

26 AZEVEDO, Luciene Almeida de. Autofição e literatura contemporânea, 2008.

27 KLINGER, Diana. Escrita de si como performance, 2008, p. 22.

28 Ibidem, p. 23.

29 AIRA, César. Nouvelle Impressions du Petit Maroc, 2011, p. 33. 
pessoal do escritor aparece como a sua construção teórica por excelência ${ }^{30}$. Neste movimento - que, segundo Aira, passa por um "salto fuera de su obra y de su persona" - podemos pensar então, junto com Klinger, que os textos ficcionais e a atuação do escritor (sua vida pública) tornam-se instâncias de atuação do eu indissociáveis entre si, que produzem, ambas, a figura do autor. Assim, o autor deixa de ser um sujeito pleno, "verificável", para tornar-se sujeito de performance; produto de uma construção tanto literária quanto "vivencial", o autor se performatiza em ambos os espaços: no texto ficcional e na "vida mesma". É justamente esse conceito de performance que desvela o caráter teatralizado da imagem do autor ${ }^{31}$.

\section{Uma escritura comunitária}

Assumir a condição performada do escritor implica em refletir sobre o processo de construção dessa condição ${ }^{32}$. Em entrevista concedida a Bernard Bretonnière ${ }^{33}$, quando nos afirma que, para ele, "a literatura não tem outra função a não ser a de pôr em cena um escritor", Aira continua, não sem um tom provocativo, dizendo que a "obra é o traço de um escritor. Eis onde nos encontramos, atualmente. Se existissem outros meios para se tornar escritor talvez fosse melhor" ${ }^{34}$. Essa insinuação de que, talvez, existissem outros modos de fazer-se escritor aparece também em La Nueva Escritura (2000). Se em Petic Maroc a sua incitação para que o escritor dê "un salto fuera de su obra y de su persona" e crie seu "mito personal del escritor" 35 , busca sobretudo desvincular a imagem do escritor da posição de conhecedor e diletante sobre a própria obra, e fazer dessa imagem um espaço de intervenção ficcional; em La Nueva Escritura, em que defende uma radicalidade vanguardista do fazer artístico que se fundamenta na reinvenção do processo artístico através do procedimento, Aira - de novo, não desprovido de um tom provocativo - argumenta que:

La profesionalización implica una especialización. Por eso las vanguardias vuelven una y otra vez, en distintas modulaciones, a la famosa frase de

\footnotetext{
30 Ibidem, p. 43-44.

31 KLINGER, Diana. Escrita de si como performance, 2008, p. 24. Para Azevedo, na autoficção o autor retorna "não mais como instância capaz de controlar o dito, mas como referência fundamental para performar a própria imagem de si" (AZEVEDO, Luciene Almeida de. Autoficção e literatura contemporânea, 2008, p. 34, grifo meu).

32 Essa condição de escritor, contudo, de maneira alguma é reconhecida a partir de alguma essência. Como nos diz o próprio Aira em Petit Maroc: “'escritor' es algo que nunca tiene confirmación, es una creencia en suspenso" (AIRA, César. Nouvelles Impressions du Petit Maroc, 2011, p. 39).

33 Entrevista acrescentada à edição brasileira de Nouvelles Impressions du Petit Maroc (Ibidem, p. 55-65).

34 Ibidem, p.61.

35 Ibidem, p. 44.
} 
Lautréamont: 'La poesía debe ser hecha por todos, no por uno'. Me parece que es erróneo interpretar esta frase en un sentido puramente cuantitativo democrático, o de buenas intenciones utópicas. Quizá sea al revés: cuando la poesía sea algo que puedan hacer todos, entonces el poeta podrá ser un hombre como todos, quedará liberado de toda esa miseria psicológica que hemos llamado talento, estilo, misión, trabajo y demás torturas. Ya no necesitará ser un maldito, ni sufrir, ni esclavizarse a una labor que la sociedad aprecia cada vez menos ${ }^{36}$.

Invertendo essa espécie de "emancipação" do escritor de que fala Aira, podemos reconhecer a dupla implicação ${ }^{37}$ desse processo: se por um lado repensar o procedimento libera o escritor de uma concepção cristalizada que se formulou acerca de seu ofício, se, através do procedimento, a reinvenção da escritura passa por uma reinvenção também do escritor; na mesma medida, o movimento de voltar-se para o procedimento, implica em uma indiferenciação entre os modos de fazer arte e os outros modos de fazer.

A colocação de Aira propõe uma renúncia do escritor à sua distinção enquanto "profissional da literatura", propõe um abandono do altar. Há toda uma política uma cena, uma atitude e criatividade próprias ao escritor; um tipo de fundação, proferimento e realização literária, em suma: uma legitimidade mítica do escritor que já não é possível. Jean-Luc Nancy, em O mito interrompido, segunda parte do livro A comunidade inoperada (2016), entende que o pensamento da escritura tornou impossível essa política literária segundo a qual operava o mito do escritor moderno. O mito do escritor está interrompido, diz $\mathrm{Nancy}^{38}$. Esta interrupção, contudo, não significa o desaparecimento do escritor, senão o surgimento de uma voz singular. O escritor torna-se o que Aira chamou no trecho acima de "un hombre como todos". Nos termos de Nancy, interrompido o seu mito, o escritor não desaparece, mas sua presença passa a se dar enquanto voz singular. E a singularidade dessa voz toma lugar na experiência literária da comunidade.

36 Idem, La nueva escritura, 2000.

37 Essa dupla implicação coincide justamente com as duas dimensões que apontei acima como sendo as que pretendo investigar na criação de um mito pessoal do escritor Mario Bellatin: 1) a condição ambígua, precária e insatisfatória do escritor criado; 2) procedimentos de escritura que convocam o leitor, o outro, ao espaço comunitário da criação.

38 Para Jean-Luc Nancy, a literatura é um gesto que expõe o limite em que se dá a comunicação de seres finitos singulares, na medida em que ela é a voz do mito e da comunidade interrompidos. A interrupção do mito, para Nancy, diz respeito à desunião dos sentidos do mito, operada pelo pensamento estrutural do mito (o "mito do mito"). Sendo o mito essencialmente comunitário, também à comunidade são essenciais a força e a fundação míticas, de modo que a interrupção do mito implica na interrupção também da comunidade. 
Mas essa comunidade de que nos fala Nancy não é um lugar, tampouco uma nação, uma família ou um corpo coletivo fundido; a comunidade que Nancy está tentando pensar é apenas o comparecimento das singularidades finitas, ou seja, o reconhecimento de uma espécie de socialidade ontológica segundo a qual "não se dá ser singular sem um outro ser singular" ${ }^{\prime 39}$ : o ser é sempre ser-em-comum ${ }^{40}$. A voz singular do escritor é singular, porém em comum.

Desse modo, a ideia de uma literatura comunitária ${ }^{41}$ parte de uma compreensão de comunidade inoperante, desobrada: uma comunidade que não produz nenhum obra e tampouco se produz enquanto obra. Uma comunidade sem comunhão, sem algo em comum, que se funda e se assume justamente na impossibilidade de realizar-se em obra. Ela é somente "a prática de uma partilha de vozes, de uma articulação pela qual somente há singularidade exposta em comum" 42 .

E a literatura que se articula enquanto voz singular nessa e dessa comunidade desobrada é sempre a reiteração de um gesto inaugural que expõe o limite e interrompe a cena mítica. $\mathrm{Na}$ escritura da comunidade, o herói mítico - como o escritor - se interrompe a si mesmo e diz a verdade: que ele não é um herói, que não há herói, ninguém que apresente e assuma sozinho o heroísmo da vida e morte de seres comumente singulares. É dessa maneira que o escritor se interrompe e consigo interrompe todas as falas fundadoras. A voz singular é, ao mesmo tempo, a voz de uma singularidade e a interrupção de uma voz geral, mítica.

Quando César Aira escreve em Petit Maroc sobre a construção de um "mito pessoal do escritor", ele não o faz no sentido de propor uma reatualização do mito do escritor interrompido, mas justamente o contrário. Assim como, para Klinger, o autor que retorna na autoficção não retorna ileso senão tendo que se haver com o descentramento do sujeito operado a partir da década de 1960, o "mito pessoal do escritor" de que fala Aira funciona como uma convocação à renúncia ao mito interrompido, ao abandono da política literária do escritor moderno. A construção

39 NANCY, Jean-Luc. A comunidade inoperada, 2016, p. 60.

40 Nancy entende que ser é sempre ser em comum: "O ser em comum significa que os seres singulares não são , não se apresentam senão a medida em que comparecem, ou são expostos, apresentados ou ofertados uns aos outros. Essa comparição não se acrescenta ao seu ser, mas é seu ser que vem a sê-la" (Ibidem, p. 100).

41 Ao trabalhar com a ideia de uma literatura comunitária ou comunismo literário, o próprio Nancy admite que esta é uma noção, antes de tudo, provocativa. A provocação está em que os dois termos que compõe esta ideia - "literatura" e "comunismo" - exigem ser radicalmente repensados. Investigar um gesto provocativo de Mario Bellatin em diálogo com a noção de uma literatura comunitária exige essa mesma mesma reformulação radical dos termos.

42 Ibidem, p. 128. 
do mito pessoal do escritor coincide com a assumpção que o escritor faz de si mesmo enquanto voz singular que se oferece à comunidade como uma história entre outras ${ }^{43}$.

\section{O gesto provocativo bellatiniano}

Após esse panorama sobre os conceitos mobilizados no presente trabalho, voltemos a Mario Bellatin. Como já foi dito, em Underwood Portátil, Disecado e Escribir sin escribir, podem ser percebidos dois traços característicos que atravessam os três textos: 1) a presença da figura do autor, incessantemente sendo colocada em questão; 2) um procedimento de escritura fragmentário e que parece "reciclar" determinados relatos e modos de contar. A seguir, proponho que essas duas dimensões dos textos de Bellatin operam de modo integrado em um mesmo gesto de escritura insistentemente provocativo. Aqui, gesto é entendido no sentido que Giorgio Agamben ${ }^{44}$ atribui ao termo, quando diz que

[s]e chamarmos de gesto o que continua inexpresso em cada ato de expressão, poderíamos afirmar então que [...] o autor está presente no texto apenas em um gesto, que possibilita a expressão na mesma medida em que nela instala um vazio central.

\section{A provocação através da construção de uma figura autoral ambígua.}

O primeiro sentido em que entendo o gesto provocativo bellatiniano diz respeito à ambiguidade com que o mito pessoal do escritor é criado, na medida em que essa criação expõe, testa e performa os impasses com que tem de se haver a função autoral na contemporaneidade.

Ainda que cada qual a seu modo, os três textos selecionados se constroem em uma interface entre vida e obra, que, ao meu ver, tensiona o procedimento de autofiguração bastante explorado na obra bellatiniana, voltando-o sobre si mesmo. Longe de pretender representar a vida no texto ou de, por outro lado, explicar sua escritura a partir de elementos biográficos, através do movimento autoreflexivo conjunto sobre a própria obra e a própria vida, inserindo-as ambas no registro ficcional,

43 "Assim, uma vez que o mito é interrompido, a escritura nos conta ainda nossa história. Mas não é mais uma narrativa - nem grande, nem pequena - é muito mais uma oferenda: uma história que nos é ofertada. Ou seja, que algo do evento - e do advento - nos é proposto, sem que um desenvolvimento nos seja imposto. O que nos é ofertado é que a comunidade chega a acontecer, ou melhor, é que algo em comum chega a nos acontecer. Nem uma origem, nem num fim: alguma coisa em comum. Somente uma fala, uma escritura - partilhadas, nos partilhando" (Ibidem, p. 113).

44 AGAMBEN, Giorgio. "O autor como gesto”, Profanações, 2007, p. 52. 
porém referencial de sua escrita, nestes três textos, Bellatin parece operar o que César Aira reconhece como a função da literatura para ele: colocar em cena um escritor ${ }^{45}$. E um escritor que não precede o seu texto, mas que nasce com ele, que se inventa a si próprio na medida em que escreve ${ }^{46}$.

A ambiguidade na criação deste mito pessoal do escritor Mario Bellatin, contudo, reside no fato de que, na mesma medida em que cria o seu mito - ou seja, em que formula uma figura autoral através do movimento autoreflexivo em que se pergunta sobre a origem de sua escritura, de seus livros, sobre a sua trajetória no campo literário em diálogo com acontecimentos de sua vida pessoal, sobre a formulação de um projeto literário próprio etc. -, Bellatin frustra a possibilidade dessa figura autoral e evidencia a sua precariedade, colocando em questão o escritor criado através de diversas maneiras: seja pelo próprio conteúdo de suas reflexões sobre a escritura ${ }^{47}$, seja pela exacerbação da presença do autor nos textos como tentativa de aboli-la por meio de uma saturação acumulada ${ }^{48}$, seja pela convocação do espectador como agente ativo no espaço comunitário da criação.

\section{a) provocação através de determinados procedimentos de escritura.}

O segundo sentido em que entendo o gesto provocativo bellatiniano diz respeito aos procedimentos de escritura mobilizados por Bellatin e os efeitos de leitura que eles são capazes de suscitar. Podemos pensar, principalmente, em dois procedimentos de escritura centrais nos textos selecionados.

45 AIRA, César, Nouvelles Impressions du Petir Maroc, 2011, p. 61.

46 Pode-se pensar neste escritor concomitante ao próprio texto conforme distinção que Roland Barthes propõe entre "Autor" e "Escritor moderno": "O Autor, quando se crê nele, é sempre concebido como o passado de seu livro: o livro e o autor colocam-se por si mesmos numa mesma linha, distribuída como um antes e um depois: considera-se que o Autor nutre o livro, quer dizer que existe antes dele, pensa, sofre, vive por ele; está para a sua obra na mesma relação de antecedência que um pai para com o filho. Pelo contrário, o escritor moderno nasce ao mesmo tempo que seu texto; não é, de forma alguma, dotado de um ser que precedesse ou excedesse a escritura, não é em nada o sujeito de que o seu livro fosse o predicado; outro tempo não há senão o da enunciação, e todo texto é escrito eternamente aqui e agora." (BARTHES, Roland. "A morte do Autor", 2004, p. 61).

47 Por exemplo, em Underwood Portátil: "Cuando comencé a escribir estaba convencido de que un creador debía construirse ese lugar, el de su propia voz. Rápidamente constaté que aquello era casi imposible [...]" (BELLATIN, Mario. Underwood Portátil,Obra reunida, 2013, p. 499).

48 É também o próprio narrador de Mario Bellatin em Escribir sin escribir quem formula essa possível forma de fazer desaparecer o autor. "Ya que cuando traté de omitir la presencia del creador de los textos no conseguí resultado alguno en este sentido, pues a pesar de todos los esfuerzos los textos siempre seguían siendo de su autor, quizá con la exacerbación de la presencia constante del escritor se logre su abolición por medio de una saturación acumulada" (BELLATIN, Obra reunida 2, 2014, p. 17, grifo meu). 


\section{i. Procedimento de repetição.}

Parte desse gesto provocativo se manifesta no procedimento de auto-apropriação49 e repetição com que Bellatin constrói esse escritor que põe em cena. Nos três textos selecionados, são justamente os Eventos de Escritura que se tornam objetos dessa repetição. Cada texto elabora um relato dos mesmos Eventos, às vezes com as mesmas palavras e expressões, mas nunca de maneira idêntica: sempre há alteração de uma palavra, acréscimo ou remoção de alguma expressão ou detalhe. Em relação à encenação de Perros Héroes50, por exemplo, diferentemente do relato feito em Underwood Portátil, em Disecado, o narrador acrescenta que o cão ficou imóvel no altar durante "veinticinco minutos de tensión" 51; acrescenta também que, no artigo escrito por um crítico que participou da ação, sobre as supostas encenações de Perros Héroes - supostas porque nunca aconteceram -, contava-se nesse artigo que, nas encenações, os cães colocados no altar eram substituídos de tempo em tempo por exemplares empalhados, de madeira, ou até mesmo, se deixava o espaço vazio. 52 Além disso, se, em Underwood Portátil, o narrador conta que a encenação de Perros Héroes "tenía como una de sus finalidades preguntarse sobre el papel del creador frente al objeto creado"53; em Escribir sin escribir, o narrador nos conta que a ideia surgiu de uma vontade de criar um conceito sobre o livro. No entanto, essas variações, esses acréscimos e essas contraposições, ao mesmo tempo em que introduzem modificações no texto e ampliam sua proliferação de sentidos - na medida em que toda a repetição se faz repetição de uma diferença que lança luz sobre outra possível dimensão do que foi narrado -, produzem também um efeito aborrecedor de repetição - do tipo "mas eu já li exatamente isso", "eu já sei o que ele vai falar"; efeito esse que não se resume aos relatos dos Eventos de Escritura, mas que

49 Procknov, fala do procedimento de apropriação como um dos mecanismos medulares da obra de Bellatin, consistindo na "inserção dos mesmos elementos (fragmentos, frases, personagens) em obras diversas" (PROCKNOV, Rafaela Cassia. Uma estética da existência: vida e escritura em Mario Bellatin, 2013, p. 27). A ideia de apropriação remete a um "princípio de refuncionalização de peças", a partir do qual os elementos apropriados não são pensados como deturpações em relação a uma matriz, mas como peças de uma engrenagem, a escritura. Aqui, utilizo o termo auto-apropriação justamente para enfatizar o movimento que a obra perfaz sobre si mesma, e me detenho sobre o efeito de repetição que este procedimento exerce sobre o leitor.

50 Ver relatos inteiros sobre esta ação em BELLATIN, Obra reunida, 2013, p. 497-498; Idem, Obra reunida 2, 2014, p. 12-14 e Ibidem, p. 219-222.

51 Ibidem, p.221.

52 Ibidem, p.220.

53 BELLATIN, 2013, p. 499. 
parece atravessar toda a obra de Mario Bellatin devido a sua própria lógica autofágica54. Reinaldo Laddaga55 descreve a impressão que o texto nos passa:

\begin{abstract}
A todos aquellos que estén familiarizados con la obra de Mario Bellatin debe pasarles lo que me pasó a mí pocos minutos después de comenzar Lecciones para una liebre muerta: que les parece que ya han leído lo que están leyendo, que ya han visto a estos mismos personajes haciendo las mismas cosas, que ya han encontrado antes los mismos nombres asociados a las mismas, pequeñas, truncadas historias.
\end{abstract}

Podemos pensar que a sensação de "já haver lido o que se está lendo" de que nos fala Laddaga - e que, conforme Samuel Steinberg, mencionado por Cote Botero parece haver se intensificado após a virada reflexiva que o projeto bellatiniano tomou ${ }^{56}$-, essa sensação carrega consigo uma provocação dirigida ao leitor - algo como: você de novo por aqui? - de modo que, não só o texto se repete, mas, em seu movimento repetitivo, acusa o leitor de também estar voltando a passar por ali, ou seja, voltando a assumir a mesma posição imóvel, passiva, com a qual se havia apresentado diante do livro anterior, à espera de algo novo. Nesse sentido, a própria construção textual autofágica de Mario Bellatin parece endereçar ao leitor aquela mesma pergunta que ele, Bellatin, quis dirigir à plateia diante do cão no altar: “o que é que você está fazendo sentado aí - de novo?”.

ii. Eventos de Escritura.

A provocação mobilizada pelo efeito de aborrecimento, de repetição, de imobilidade obsessiva da escritura, parece ter seu correlato na própria noção de Eventos de

54 A expressão é de Andrea Cote Botero, quando aborda o caráter reincidente da escritura de Bellatin sobre si própria: "El quehacer literario funciona aquí como una serpiente que se muerde la cola; se trata de una escritura autofágica que se alimenta cada vez más de sus propias referencias, pero estas, como hemos visto, no proviene tan sólo de sus historias publicadas, sino de todos los elementos de su práctica que aun sin ser verbales logran generar escritura y terminan, por tanto, integrados en esta [...]. Se trata, más bien, de un principio de acumulación que opera en la ficción de este autor donde toda escritura es material de escritura, como lo son también las acciones diversas que tienen lugar en momentos de edición, circulación o divulgación de un proyecto literario" (COTE BOTERO, Andrea. Mario Bellatin: El Giro Hacia El Procedimiento y La Literatura Como Proyecto, 2014, p. 69-70, grifos meus).

55 LADDAGA, Reinaldo. Espectáculos de realidad. Ensayo sobre la narrativa latinoamericana de las últimas dos décadas, 2007, 164.

56 "La costumbre de hacer libros que refieran constantemente a las características y análisis de su propia escritura se acentúa en la obra de Bellatin a razón del avance de su producción literaria. En su artículo 'To begin writing: Bellatin, reunited' Samuel Steinberg propone una periodización que permite identificar el surgimiento de una etapa marcadamente auto-reflexiva em Bellatin. Steinberg sugiere que la publicación del volumen de Obras Completas (2005) constituye el punto de inflexión en que la obra se cierra en diálogo crítico consigo misma" (COTE BOTERO, Mario Bellatin: El Giro Hacia El Procedimiento y La Literatura Como Proyecto, 2014, p. 104). 
Escritura de dois modos: 1) enquanto procedimento de escrita - na medida em que ela põe em questão tanto a estreiteza dos procedimentos convencionais de escrita quanto as posições de escritor/produtor e leitor/consumidor -; e 2) em seu próprio conteúdo: a alegoria do cão, por exemplo - ou, como na versão de Disecado, do espaço vazio no altar -, diante do qual os espectadores permanecem imóveis, contemplando, parece perfazer a mesma provocação que a construção repetitiva do mito pessoal nos textos, mas, agora, conforme propõe a noção de Eventos de Escritura, sem a mediação das palavras.

\section{Bellatin e a busca pela condição comunitária da literatura}

Esboçado o gesto provocativo, cabe, no entanto, perguntar: que gesto provocativo é esse? ${ }^{57}$ Ou seja, o que é que ele provoca, que desafio ele coloca? Sobre o que ele convoca os outros a se manifestarem? O que ele produz?

Em outro dos Eventos de Escritura relatado em Escribir sin escribir, o narrador nos conta que o artista aldo chaparro ${ }^{58}$ está construindo-lhe uma nova prótese ${ }^{59}$ para o seu braço direito. Quando concluída, o narrador pretende entregá-la para intervenção comunitária, como forma de proposta artística:

\footnotetext{
El proyecto se abriría a otros artistas para que, a partir de ciertas normas, completen de manera colectiva el silencio de la ausencia. Siento que una acción semejante es similar a cuando un autor entrega un texto a una editorial. Al instante en que la obra termina de ser del autor e ingresa a una suerte anonimato ${ }^{60}$.
}

A relação entre braço e autor como elementos faltantes, ressaltados justamente para que se acentue a sua artificialidade, se faz marcante aqui ${ }^{61}$. No entanto, além

\footnotetext{
57 No dicionário Aurélio, são reconhecidas 11 possíveis acepções do verbo provocar. Me detenho nas seguintes: "1. Chamar a provocação ou desafio; desafiar. [...] 3. Ser causa ou motivo de; ocasionar, produzir, gerar. [...] 5. Trabalhar para que ocorra; armar aprontar, promover. 6. Chamar sobre si; atrair. [...] 9. Chamar alguém para manifestar-se a propósito de um assunto ou questão. [...] 10. Incitar, estimular excitar” (AURÉLIO Buarque de Holanda Ferreira. Dicionário Aurélio Básico da Lingua Portuguesa, 1988, p.536). Além disso, penso aqui na afirmação de Klinger, de que o autor que retorna na autoficção "retorna não como garantia última da verdade empírica e sim como provocação, na forma de um jogo que brinca com a noção do sujeito real' (KLINGER, Diana Irene. Escritas de si, escritas do outro: autoficcção e etnografia na narrativa latino-americana contemporânea, 2006, p.45).

58 No texto, Bellatin escreve assim os nomes próprios.

59 Bellatin não tem braço direito, tema que reincide exaustivamente ao longo de sua obra.

60 BELLATIN, Mario. Obra reunida 2, 2014, p. 17.

61 “¿la inclusión de lo artificial resalta el vacío o genera una simulación que oculta su existencia? Como puede apreciarse, en los intersticios de la interrogación, las problemáticas poéticas en torno al artifício
} 
disso, se faz marcante o gesto de Bellatin de entregar o próprio corpo à intervenção artística - da mesma maneira como alguém entrega um livro à editora -, desfazendo-se da autoridade autoral sobre ele. A conformação de um gesto provocativo bellatiniano, portanto, sugere uma orbitação em torno da pergunta pelo estatuto público da obra e do questionamento da convencionalidade das posições assumidas por artista e espectador - questionamento esse que se alinha com as considerações de César Aira e Jean-Luc Nancy.

Por que as pessoas se dispõe a assistir um cão no altar por quase meia hora sem dizer nada, como se estivessem participando de uma espécie de culto? Ou, por que elas vão a um congresso escutar as ideias de um autor e se incomodam quando, embora sejam as mesmas ideias que estão sendo discutidas ali, o corpo do autor não está presente no espaço ${ }^{62} \mathrm{O}$ gesto provocativo de Bellatin, portanto, parece atravessar sua obra - literária e extraliterária (se é que a essa altura ainda faz sentido essa distinção) - e lançar um desafio, uma convocação à compreensão do ato literário como ato invariavelmente comunitário: exposição de uma voz singular em comum.

Leonel Cherri ${ }^{63}$, aproximando o caso de Bellatin das formulações de Aira em La nueva escritura, diz que, no caso do escritor mexicano, se trata de "poner en juego el estatuto público de la obra, es decir, no solo una consigna estética sino un impulso ético. [...] Bellatin, más bioestético, no se ha cansado de repetir que todo, incluso su propio cuerpo, se trata de un 'jardín público', es decir, 'un espacio anónimo donde todos y cada uno tenemos la responsabilidad de mantenerlo en perfectas condiciones' (¿Le gusta este jardín que es suyo? No deje que sus hijos lo destruyan, p.67)". Esse reconhecimento do "espaço anônimo" em que a obra e o corpo do artista se produzem instaura uma ruptura em determinada ordem na qual o fazer artístico é compreendido. É nesse sentido que, por fim, a provocação do gesto de Mario Bellatin pode ser investigada em sua dimensão ético-política, enquanto uma interrupção da ordem hierárquica estabelecida entre escritor e leitor através da revelação de um comum prévio a qualquer ordem: a contingência de toda ordem. O gesto de Bellatin instaura uma nova partilha do sensível ${ }^{64}$, na medida em que expõe os lugares-comuns

se articulan con las del autor y su imagen" (CHERRI, Leonel. La repetición como experiencia, 2015, p. 9). 62 Referência ao Congreso de dobles de escritores, um dos Eventos de Escritura mais famosos realizados por Bellatin, que consistiu em um congresso de escritores mexicanos contemporâneos em Paris, ao qual, no entanto, não compareceram os escritores, conforme anunciado, senão atores treinados pelos próprios escritores durante seis meses para exporem suas ideias.

63 Ibidem, p. 7.

64 Aqui estou propondo investigar o gesto bellatiniano a partir da noção de partilha do sensivel de Rancière e de sua compreensão de política. Segundo o filósofo, a partilha do sensível consiste no "sistema de evidências sensíveis que revela, ao mesmo tempo, a existência de um comum e dos recortes que nele definem lugares e partes respectivas" (RANCIËRE, Jacques. A partilha do sensivel: estética e política, 2009 , p. 15). Em O Desentendimento, Rancière entende como política justamente a interrupção de uma 
de escritor/produtor e espectador/consumidor a uma tensão: na medida em que interrompe o próprio mito e preenche o altar para revelar que ele está vazio.

Assim, tanto os jogos de Bellatin com a figura autoral quanto o questionamento da instituição literária que seus Eventos de Escritura e sua lógica autoapropriativa operam, podem ser compreendidos, ambos, como dois movimentos de um mesmo gesto que qualifiquei aqui de provocativo. Esse gesto, além de tudo, configura uma busca por estratégias de reinvenção da literatura por meio da própria literatura; busca essa que não deixa de passar por uma transgressão do convencional ${ }^{65}$ e que não se desvincula de um pensamento sobre formas-de-vida a serem experimentadas. A provocação, portanto, seria, justamente, a de uma compreensão da literatura como fala que põe em jogo o ser em comum. Assim, o gesto que essa compreensão conforma é o de uma busca pela condição comunitária do ato de escritura.

\section{Referências Bibliográficas}

AGAMBEN, Giorgio. O autor como gesto. In: AGAMBEN, Giorgio. Profanações. São Paulo: Boitempo, 2007. p. 55-63.

AIRA, César. La nueva escritura. Publicado en el Boletín n ${ }^{\circ} 8$ del Centro de Estudios de Teoría y Crítica Literária (Universidad Nacional de Rosario, Rosario, octubre de 2000, p.165-170). Disponível em: www.multiversos.com.ar/teoria-literaria/la-nueva-escritura-cesar-aira. Acesso em: 21 agosto de 2019 .

AIRA, César. Nowvelles Impressions du Petit Maroc. Trad. Jorge Wolff. Florianópolis: Cultura e Barbárie, edição bilíngue [português/castelhano], 2011.

ARFUCH, Leonor. O espaço biográfico: dilemas da subjetividade contemporânea. Trad. Paloma Vidal. Rio de Janeiro: EdUERJ, 2010.

AURÉLIO Buarque de Holanda Ferreira. Dicionário Aurélio Básico da Lingua Portuguesa. Rio de Janeiro: Editora Nova Fronteira S.A., 1988.

determinada ordem social fundada sobre determinada partilha do sensível. A política revela o dano que a ordem institui no comum, isto é, o comum que antecede qualquer ordem, a "anarquia última sobre que repousa toda hierarquia. [...]. Pois o fundamento da política [...] é a ausência de fundamento, é a pura contingência de toda ordem social. Há política simplesmente porque nenhuma ordem social está fundada na natureza, porque nenhuma lei divina ordena as sociedades humanas" (Idem, $O$ desentendimento: política e filosofia, 1996, p. 30, grifo do autor).

65 Como diz Ana Cecília Olmos (2011), políticas de escritura que trabalham nas margens do institucionalizado, como forma de resistir às convenções, explorando e transgredindo as fronteiras dos gêneros literários, diante de um cenário latino-americano em que a arte se encontra "ameaçada de dissolução pelas condições que impõe a lógica do mercado e o avanço da tecnologia e suas novas linguagens" (OLMOS, Ana Cecília. "Transgredir o gênero: políticas da escritura na literatura hispano-americana atual", Revista de estudos de literatura brasileira contemporânea, 2011, p. 11). 
AZEVEDO, Luciene Almeida de. Autofiçãa e literatura contemporânea. Revista Brasileira de Literatura Comparada, n.12, 2008.

BELLATIN, Mario. Obra reunida. Tres Cantos, Madrid: Alfaguara. Santillana Ediciones Generales, 2013.

BELLATIN, Mario. Obra reunida 2. México: Alfaguara. Santillana Ediciones Generales, 2014.

BARTHES, Roland. A morte do Autor. In: BARTHES, Roland, O rumor da língua. Trad. Mario Laranjeira. São Paulo: Martins Fontes, 2. ed., 2004. p. 57-64.

CHERRI, Leonel. La repetición como experiencia. Facultad de Humanidades y Ciencias (FHUC) de la Universidad del Litoral (UNL). Apresentado no "IV Congreso Internacional Cuestiones Críticas" em versão adaptada, com o título La imagen del autor en Mario Bellatin y el pequeño dispositivo pedagógico, 2015.

COTE BOTERO, Andrea. Mario Bellatin: El Giro Hacia El Procedimiento y La Literatura Como Proyecto. Dissertation (Doctor of Philosophy). University of Pennsylvania, 2014.

DELEUZE, Gilles. A vida como obra de arte. In: DELEUZE, Gilles, Conversações (1972-1990). Trad. Peter Pál Pelbart. São Paulo: Editora 34, 2013. p. 122-130.

FOUCAULT, Michel. O que é um autor? In: FOUCAULT, Michel. Ditos e Escritos. Vol.III. Estética: literatura e pintura, música e cinema. Organização e seleção de textos: Manoel Barros da Motta. Tradução: Inês Autran Dourado Barbosa. Rio de Janeiro, Forense Universitária, 2. ed., 2009. p. 264-298.

KLINGER, Diana Irene. Escritas de si, escritas do outro: autoficç̧ão e etnografia na narrativa latino-americana contemporânea. 204f. Tese (Doutorado em Letras), Universidade do Estado do Rio de Janeiro, Rio de Janeiro, 2006.

KLINGER, Diana. Escrita de si como performance. Revista Brasileira de Literatura Comparada, n. 12, 2008. p. 11-30.

LADDAGA, Reinaldo. Espectáculos de realidad. Ensayo sobre la narrativa latinoamericana de las últimas dos décadas. Revista Comunicaçãoépolítica, Rosario, Argentina: Beatriz Viterbo, v. 24, n. 3, 2007. p. $159-178$.

LINK, Daniel. El escritor como "forma-de-vida". Conferência leída en el marco del I Festival Internacional de Literatura en Tucumán. San Miguel de Tucumán: 11 de julio de 2015 (Versão adaptada em Revista Landa n. 0, ano 2012).

NANCY, Jean-Luc. A comunidade inoperada. Trad. Soraya Guimarães Hoepfner. Rio de Janeiro: 7Letras, 2016.

OLMOS, Ana Cecília. Transgredir o gênero: políticas da escritura na literatura hispano-americana atual. Revista de estudos de literatura brasileira contemporânea, n. 38, jul./dez. 2011. p. 11-21.

PROCKNOV, Rafaela Cassia. Uma estética da existência: vida e escritura em Mario Bellatin. 189f. Dissertação (Mestrado) - Faculdade de Filosofia, Letras e Ciências Humanas da Universidade de São Paulo. Departamento de Letras Modernas. São Paulo, 2013.

RANCIÈRE, Jacques. A partilha do sensivel: estética e política. Trad. Mônica Costa Netto. EXO experimental (org.). São Paulo: Editora 34, 2009.

RANCIÈRE, Jacques. O desentendimento: politica e filosofia. Trad. Ângela Leite. São Paulo: Editoria 34, 1996.

SAER, Juan José. O conceito de ficção. Trad. Joca Wolff. Revista Sopro, n. 15, ago. 2009. 
Submissão: 02/05/2020

Aceite: $20 / 08 / 2020$

https://doi.org/10.5007/2176-8552.2019.e73061

Esta obra foi licenciada com uma Licença Creative Commons Atribuição-NãoComercial 4.0

Universidade Federal de Santa Catarina - 2o Semestre de 2019 